\title{
CagA Helicobacter pylori Seropositivity in Asymptomatic, Apparently Healthy, Young Adult Egyptian Food Handlers
}

Yahia Zakaria Gad, Amany Mohammad Hassan

\begin{abstract}
Background/Aim: Infection with CagA Helicobacter pylori (H. pylori) positive strain is a risk factor for the development of atrophic gastritis and gastric adenocarcinoma. This study investigated the seroprevalence of $H$. pylori and its virulent strains CagA in Egyptian food handlers.
\end{abstract}

Subjects and methods: A total of 365 eligible male subjects participated in the initial study. Venous blood samples were collected from all participants for assessment of $H$. pylori specific IgG and serum CagA antibodies.

Results: Out of 365 subjects, 310 were reactive to $H$. pylori. Out of them, CagA was detected in $143 \mathrm{H}$. pylori-infected subjects. CagA antibodies were more common in cigarette smokers (<0.001), living in high crowding index $(<0.001)$, with low family income $(<0.01)$ and sharing their bedrooms during childhood $(<0.001)$.

Conclusion: Our data revealed a high prevalence of CagA virulent strains among asymptomatic apparent food handlers of Egypt. Emergency surveillance mechanisms should be developed for containment of $H$. pylori infection in Egypt.

Abbreviations: H. pylori: Helicobacter pylori; CagA: Cytotoxin associated gene $\mathrm{A}$.

Keywords: Cytotoxin-associated gene A, H. pylori, Egyptian food handlers.

How to cite this article: Gad YZ, Hassan AM. CagA Helicobacter pylori Seropositivity in Asymptomatic, Apparently Healthy, Young Adult Egyptian Food Handlers. Euroasian J Hepato-Gastroenterol 2012;2(1):20-23.

Source of support: Nil

Conflict of interest: None declared

\section{INTRODUCTION}

Helicobacter pylori (H. pylori) is a Gram-negative, spiral, microaerophilic bacterium that resides in a neutral microenvironment between the mucus and the superficial epithelium of the stomach. ${ }^{1}$ This microorganism infects the stomach of more than $50 \%$ of the human population worldwide and is responsible for upper gastrointestinal diseases in humans, including gastritis, gastric ulcer, duodenal ulcer, gastric adenocarcinoma and gastric B-cell lymphoma. ${ }^{2}$ In developing countries, the prevalence of this infection can be as high as $80 \% .{ }^{3} \mathrm{CagA}$ (a product of CagA gene) is one of the most important putative virulence factors of $H$. pylori and contributes to the developing different H. pylori related outcomes in Western countries ${ }^{4}$ and infection with a CagA-positive strain is a risk factor for the development of atrophic gastritis ${ }^{5}$ and gastric adenocarcinoma. ${ }^{6}$ However, little is known about $H$. pylori local demographic characteristics. Therefore, the aim of this study is to investigate the seroprevalence of $H$. pylori and its virulent strains CagA and their possible related risk factors among food handlers from Egypt.

\section{SUBJECTS AND METHODS}

Subjects were randomly selected among food handlers recruiting at the Mansoura local Ministry of Health during periodic health assessment in 2010. We started with 407 males and 127 females. All answered the study questionnaire and performed physical measurements. Forty-two males and all females refused to give blood sampling and were excluded from the study. Subjects gave a written consent to participate in the initial study and the subsequent $\mathrm{H}$. pylori serology. They were no recent history of alcohol consumption, or any drugs or medications during the last 2 months. Thus, nonfasting venous sample was collected from 365 male participants and stored at $-20^{\circ} \mathrm{C}$ for subsequent analysis. ${ }^{7}$

The titers of $H$. pylori were estimated by an ELISA kit (Premier, Meridian Diagnostics, Cincinnati, Ohio, USA). The assessment of CagA antibodies were accomplished in the sera using recombinant CagA antigen, or v220. ${ }^{6}$ The assay of CagA had $92 \%$ sensitivity and $96 \%$ specificity that was preevaluated in 62 patients from another studying whom the CagA status was assessed directly by western blot in gastric biopsy specimens (Helicoblot 2.0, Genelabs Diagnostics, Singapore). This level of accuracy is comparable with that described for the original serological assay. ${ }^{6}$

Univariate analysis was performed for all variables to ascertain significance as predictive factors of $H$. pylori infection using Pearson's Chi-square test for categorical and ordinal variables and t-test for continuous variables. Results $<0.05$ were considered to be statistically significant. Data analyzes were performed using SPSS 15.0 (SPSS, Chicago, IL, USA).

\section{RESULTS}

A total of 365 asymptomatic male subjects (age; 21-39 years), were enrolled in this study. All of them were 
asymptomatic. Of them 55 (11.28\%) subjects were tested negative and $310(88.72 \%)$ were positive for $H$. pylori antibodies. CagA antibodies were positive in 143 (46.13\%) of those tested positive for mixed antigen H. pylori (Tables 1 and 2).

Epidemiological study revealed that $H$. pylori was more common in men of rural origin (60.4 vs 29.99\%, p < 0.001), current smokers $(p<0.05)$, people of low socioeconomic standard, and comparatively lower educational level ( $\mathrm{p}<0.001)$. H. pylori was also prevalent in persons who shared bed in childhood $(\mathrm{p}<0.001)$ and high lived in places with crowding index $(\mathrm{p}<0.001)$ (Table 1$)$.

CagA antibodies were more common in cigarette smokers $(<0.001)$, living in high crowding index $(<0.001)$, with low family income $(<0.01)$ and sharing their bedrooms during childhood $(<0.001)$.

As shown in Table 2, CagA seropositivity was more among those of urban origin $(<0.05)$ and the educated group $(<0.01)$ (Table 2). Urban inhabitants admitted that $27 / 40$ $(67.5 \%)$ of them lived for years in their early life in a rural area and 41/67 (61.19\%) of those well educated worked at least 1 year in an obligatory governmental service in distant villages.

Understanding the potential pathogenicity of CagApositive strains, $7 / 143(4.89 \%)$ asymptomatic subjects performed upper gastrointestinal endoscopy. The data revealed that all of them had apparently normal gastric mucosal in macroscopic view, but, all of them had chronic superficial gastritis on histopathological examination.

\section{DISCUSSION}

Infection with $H$. pylori occurs worldwide, but the prevalence varies greatly among countries and among population groups within the same country. ${ }^{8}$ H. pylori infection is quite common, even among asymptomatic individuals. It occurs in about $10 \%$ of healthy individuals younger than age 30 , and in nearly $60 \%$ of those overage $60 .{ }^{9}$

This study revealed that only $11.27 \%$ were tested negative while the remaining subjects $(88.73 \%)$ were tested positive for mixed $H$. pylori antigens. This high prevalence is probably common in the developing countries as Brazil

\begin{tabular}{|c|c|c|}
\hline Possible risk factor & All H. pylori positive (310) & All H. pylori negative (55) \\
\hline \multicolumn{3}{|l|}{ Place of birth } \\
\hline Urban & $109(39.6 \%)^{* *}$ & $39(70.01 \%)$ \\
\hline Rural & $201(60.4 \%)^{\star *}$ & $16(29.99 \%)$ \\
\hline Current smoker & $120(30.83 \%)^{*}$ & 27 (49.99\%) \\
\hline BMI & 25.2 & 25.3 \\
\hline \multicolumn{3}{|l|}{ Adult socioeconomic factors } \\
\hline Car owner & $109(39.6 \%)^{* *}$ & $40(72.72 \%)$ \\
\hline Home owner & $212(68.38 \%)$ & $42(76.33 \%)$ \\
\hline Married & $170(54.83 \%)$ & $31(50.65 \%)$ \\
\hline Occupation in high social class & $25(8.06 \%)^{\star *}$ & $38(69.09 \%)$ \\
\hline Possession of pets & $28(9.03 \%)^{\star *}$ & $3(5.45 \%)$ \\
\hline \multicolumn{3}{|l|}{ Annual family income } \\
\hline$<3000$ Egy pounds & $69(22.26 \%)^{\star \star}$ & $51(92.73 \%)$ \\
\hline$\geq 3000$ Egy pounds & $241(77.74 \%)^{\star \star}$ & $4(7.27 \%)$ \\
\hline Municipal water & $310(100 \%)$ & $55(100 \%)$ \\
\hline Adequate sewage disposal & $305(98.38 \%)$ & $55(100 \%)$ \\
\hline \multicolumn{3}{|l|}{ Crowding index } \\
\hline$<1$ & $5(1.62 \%)^{\star \star}$ & $42(76.33 \%)$ \\
\hline$>1$ & $305(98.38 \%)^{* *}$ & $13(23.67 \%)$ \\
\hline \multicolumn{3}{|l|}{ Educational level } \\
\hline Lack of schooling & $15(4.93 \%)^{* \star}$ & $0(0 \%)$ \\
\hline Elementary & $85(20.97 \%)^{\star *}$ & $0(0 \%)$ \\
\hline Medium-High & $210(63.1 \%)^{\star *}$ & $55(100 \%)$ \\
\hline \multicolumn{3}{|l|}{ Childhood socioeconomic factors } \\
\hline Shared bedroom & $80(25.81 \%)^{* *}$ & $5(90.99 \%)$ \\
\hline Hot water tap in the house & $210(63.1 \%)^{* *}$ & $55(100 \%)$ \\
\hline Bathroom in the house & $310(100 \%)$ & $55(100 \%)$ \\
\hline Family owned a car & $5(1.62 \%)^{* *}$ & $29(54.54 \%)$ \\
\hline Father with nonmanual job & $38(12.29 \%)^{\star *}$ & $44(80 \%)$ \\
\hline \multicolumn{3}{|l|}{ Crowding index } \\
\hline$<1$ & $2(0.65 \%)^{\star \star}$ & $25(45.41 \%)$ \\
\hline$>1$ & $308(99.35 \%)^{\star *}$ & $30(54.59 \%)$ \\
\hline Possession of pets & $15(4.93 \%)$ & $3(5.45 \%)$ \\
\hline
\end{tabular}

${ }^{*} \mathrm{p}$-value $<0.05 ;{ }^{* *} \mathrm{p}$-value $<0.001$ 
where the prevalence of $H$. pylori infection is as high as $80 \% .{ }^{3}$ Low socioeconomic status, poor hygiene, inadequate sanitation and household overcrowding are associated with prevalence of $H$. pylori infection with no gender difference. ${ }^{8}$

Our data revealed that $H$. pylori was more common in men of rural origin $(p<0.001)$, current smokers $(p<0.05)$, low socioeconomic standard, low educational level $(\mathrm{p}<0.001)$ and with shared bedrooms $(\mathrm{p}<0.001)$ during their childhood and high crowding index $(\mathrm{p}<0.001)$ (Table 1).

Improvement in hygiene and living conditions have resulted in less prevalence of $H$. pylori infection; ${ }^{10}$ a statement describing the situation in the H. pylori seronegative subjects in this study.

H. pylori CagA-positivity is associated with severe disease symptoms and a higher risk of ulcerations, mucosal atrophy and gastric adenocarcinoma. ${ }^{5,6}$ H. pylori CagAseropositivity was found in $46.13 \%$ of the participants in this study and was more common among cigarette smokers $(\mathrm{p}<0.001)$, those living in crowded houses $(\mathrm{p}<0.001)$, with low family income $(\mathrm{p}<0.01)$ and those were sharing their bedrooms during childhood $(\mathrm{p}<0.01)$.
CagA-positive strains increase the expression of the nuclear factor $\mathrm{\kappa B}$ and stimulate the release of interleukin8 ; a cytokine that plays a central role in the pathogenesis of H. pylori gastritis. ${ }^{11}$ This study revealed that $7 / 7(100 \%)$ asymptomatic CagA-positive subjects had chronic superficial gastritis when upper endoscopy was performed. This finding would alert physicians about this silent pathology and other potential risks, related to CagA strains, especially if become progressive without alarming symptoms.

Epidemiological studies suggest person-to-person transmission, by either fecal-oral or oral-oral routes, to be the major mechanism for $H$. pylori transmission. In developing countries, there is evidence for both food- and water-borne transmission of $H$. pylori. Intrafamilial spread appears to play a central role in transmission of the infection in both developing and developed countries. ${ }^{12}$ It is generally believed that once $H$. pylori infection occurs, it commonly persists throughout life unless treated. ${ }^{13}$ This study found that significant CagA-positive subjects reported bedroom sharing during childhood more than CagA-negative ones; a data consistent with suggestions that potentially virulent

Table 2: Possible risk factors with CagA-positivity in the studied subjects

\begin{tabular}{|c|c|c|}
\hline Possible risk factor & CagA-positive (143) & CagA-negative (167) \\
\hline \multicolumn{3}{|l|}{ Place of birth } \\
\hline Urban & $40(27.97 \%)^{*}$ & $69(41.32 \%)$ \\
\hline Rural & $103(63.03 \%)$ & $98(58.68 \%)$ \\
\hline Current smoker & $88(73.33 \%)^{\star *}$ & $32(26.67 \%)$ \\
\hline BMI & 25.3 & 25.4 \\
\hline \multicolumn{3}{|l|}{ Adult socioeconomic factors } \\
\hline Car owner & $29(16.67 \%)^{\star *}$ & $80(47.9 \%)$ \\
\hline Home owner & $98(68.53 \%)$ & $114(68.26 \%)$ \\
\hline Married & $73(51.05 \%)$ & $97(58.08 \%)$ \\
\hline Occupation in high social class & $9(6.29 \%)$ & $17(10.18 \%)$ \\
\hline Possession of pets & $10(6.99 \%)$ & $18(10.22 \%)$ \\
\hline \multicolumn{3}{|l|}{ Annual family income } \\
\hline$<3000$ Egy pounds & $18(12.58 \%)^{\star *}$ & $51(28.98 \%)$ \\
\hline$\geq 3000$ Egy pounds & $91(63.64 \%)$ & $150(85.22 \%)$ \\
\hline Treated water & $143(100 \%)$ & $167(100 \%)$ \\
\hline Adequate sewage disposal & $138(96.5 \%)$ & $167(100 \%)$ \\
\hline \multicolumn{3}{|l|}{ Crowding index } \\
\hline$<1$ & $1(0.67 \%)$ & $4(2.3 \%)$ \\
\hline$>1$ & $142(99.33 \%)^{\star *}$ & $163(97.6 \%)$ \\
\hline \multicolumn{3}{|l|}{ Educational level } \\
\hline Lack of schooling & $6(4.19 \%)$ & $9(5.11 \%)$ \\
\hline Elementary & $39(27.27 \%)$ & $46(26.14 \%)$ \\
\hline Medium—high & $67(46.85 \%)^{*}$ & $133(79.64 \%)$ \\
\hline \multicolumn{3}{|l|}{ Childhood socioeconomic factors } \\
\hline Shared bedroom & $62(43.36 \%)^{\star *}$ & $18(10.78 \%)$ \\
\hline Hot water tap in the house & $97(56.07 \%)^{*}$ & $113(67.66 \%)$ \\
\hline Bathroom in the house & $134(100 \%)$ & $167(100 \%)$ \\
\hline Family owned a car & $2(1.39 \%)$ & $3(1.79 \%)$ \\
\hline Father with nonmanual job & $17(11.89 \%)$ & $21(12.57 \%)$ \\
\hline \multicolumn{3}{|l|}{ Crowding index } \\
\hline$<1$ & $1(0.69 \%)$ & $1(0.59 \%)$ \\
\hline$>1$ & $142(99.31 \%)$ & $166(99.41 \%)$ \\
\hline Possession of pets & $12(8.39 \%)^{*}$ & $3(1.79 \%)$ \\
\hline
\end{tabular}

${ }^{*} p$-value $<0.05 ;{ }^{* *}$-value $<0.001$ 
H. pylori strains may be acquired during childhood than other strains. ${ }^{14}$

Interestingly, CagA-seropositivity was found more in people of urban origin $(<0.05)$, and also among the educated group $(\mathrm{p}<0.01)$ (Table 2). Detailed interrogation of the urban inhabitants revealed that 27/40 (67.5\%) subjects lived for few years in their childhood in a rural area and 41/67 $(61.19 \%)$ of those well-educated persons worked at least 1 year in an obligatory governmental service jobs in distant villages with great possiblities of acquiring $H$. pylori infection there. The remaining CagA-positive subjects (22.5\%) of the former and $38.81 \%$ of the latter, probably acquired $H$. pylori infection during their adulthood. Therefore, it can be suggested that there is continuous chance of acquiring $H$. pylori infection, but with a lower risk in adults with high socioeconomic class in endemic areas.

Our data revealed a high prevalence of $H$. pylori infection and its CagA virulent strains in the studied subjects. Continuous chance of acquisition $H$. pylori infection, but with a lower risk in adults with high socioeconomic class in endemic areas, is suggested. Improvement in hygiene and living conditions for a lesser prevalence of $H$. pylori infection is advised.

\section{REFERENCES}

1. Marshal BJ, Warren JR. Unidentified curved bacilli in the stomach of patients with gastritis and peptic ulcerations. Lancet 1984;1:1311-15.

2. Blaster MJ, Atherton JC. Helicobacter pylori persistence; biology and disease. J Clin Invest 2004;113:321-33.

3. Covacci A, Telford JL, Giudice GD, et al. Helicobacter pylori virulence and genetic geography. Science 1999;284:1328-33.

4. Basso D, Navaglia L, Piva Mg, et al. Analysis of Helicobacter pylori VacA and CagA genotypes and serum antibody profile in benign and malignant gastroduodenal diseases. Gut 1998;43: 182-86.

5. Kuipers EJ, Perez-Perez GI, Meuwissen SG, et al. Helicobacter pylori and atrophic gastritis: Importance of cagA status. J Natl Cancer Inst 1995;87:1777-80.
6. Blaster MJ, Perez-Perez GI, Kleanthous H, et al. Infection with Helicobacter pylori strains possessing CagA is associated with increased risk of developing adenocarcinoma of the stomach. Cancer Res 1995;55:2111-15.

7. Shaper AG, Pocock SJ, Walker M, et al. British regional heart study: Cardiovascular risk factors in middle-aged men in 24 towns. BMJ 1981;183:179-83.

8. Perez-perez GI, Rothenbacher D, Brenner H. Epidemiology of Helicobacter pylori infection. Helicobacter 2004:Suppl(9)1: $1-6$.

9. Feldman RA. Epidemiologic observations and open questions about disease and infection caused by Helicobacter pylori In: Achtman M, Suerbaum S, (Eds). Helicobacter pylori: Molecular and cellular biology. Wymondham, United Kingdom: Horizon Scientific Press 2001:29-51.

10. Eurogast Study Group. Epidemiology of, and risk factors of Helicobacter pylori infection among 3194 asymptomatic subjects in 17 populations. Gut 1993;34;1672-76.

11. Munzenmmaier. A secreted/shed product of Helicobacter pylori activates transcription factor nuclear factor kappa B. J Immunol 1997; 159:6140-47.

12. Sinha SK, Martin B, Gold BD. The incidence of Helicobacter pylori acquisition in children of a Canadian First Nations community and the potential for parent to child transmission. Helicobacter 2004;9:59-68.

13. Lehours P, Yilmas Q. Epidemiology of Helicobacter pylori infection. Helicobacter 2007;12(Suppl 1):1-3.

14. Blaster MJ, Chyou PH, Nomura A. Age at establishment of Helicobacter pylori infection and gastric carcinoma, gastric ulcer and duodenal ulcer risk. Cancer Res 1995;55:562-65.

\section{ABOUT THE AUTHORS}

\section{Yahia Zakaria Gad (Corresponding Author)}

Assistant Professor, Department of Internal Medicine Hepatogastroenterology Unit, Mansoura Specialized Medical Hospital Mansoura University, Mansoura, Egypt, Phone: +20122 7581150 e-mail: yahiazgad@yahoo.com

\section{Amany Mohammad Hassan}

Senior Consultant, Department of Clinical Immunology, Central Laboratories, Ministry of Health, Mansoura, Egypt 